\title{
Del antifranquismo al feminismo: la búsqueda de una nueva ciudadanía del movimiento democrático de mujeres en la Transición democrática
}

From Antifrancoism to Feminism: The search for a new Citizenship of Women's Democratic Movement in Spanish Democratic Transition

\author{
Ana Belén Gómez Fernández \\ Universidad de Jaén
}

Recibido: 11-IX-2013

Aceptado: 7-IV-2014

\section{Resumen}

El objetivo de este artículo es analizar el papel del Movimiento Democrático de Mujeres en la construcción de la democracia. Una organización formada por varias generaciones de mujeres que lucharon contra la dictadura y por la construcción de un marco igualitario entre hombres y mujeres. Se analiza la evolución de este movimiento desde la denuncia de la política represiva del régimen franquista, destacando el papel de solidaridad y labor asistencial a los presos políticos, pasando por la labor en los barrios contra la carestía de vida y la falta de infraestructuras, para terminar con planteamientos plenamente feministas, desarrollando un discurso compatible con la lucha por la democracia y la libertad.

Palabras clave: Mujeres, Solidaridad, Movilización femenina, Antifranquismo, Feminismo.

\begin{abstract}
The purpose of this paper is to analyze the role of the Women's Democratic Movement in the building of democracy. An organization formed by several generations of women who fought dictatorship and struggled to develop an equal status for men and women. The analysis of the movement evolution begins with the their denunciation of repressive policies in Franco's regime, highlighting their supportive role and assistance with political prisoners. Their work in low-income districts against the high cost of living and the lack of infrastructure will be revised next. Finally. A final stage deals with the
\end{abstract}


organization's fully feminist approaches by developing solid arguments in support of the struggle for democracy and freedom.

Keywords: Women, Solidarity, Women's mobilization, Antifranco-movement, Feminism.

\section{Introducción}

A pesar de que cada vez son más abundantes los estudios relacionados con el final de la dictadura franquista y la llegada de la democracia, la bibliografía sobre el protagonismo de las mujeres durante los últimos años del régimen y su contribución a la construcción de la democracia se ha caracterizado tradicionalmente por una falta de visibilidad historiográfica. Este hecho se debe por un lado a que la transición democrática ha sido analizada en buena medida desde un punto de vista que sobrevalora el papel de ciertas personalidades y entiende el cambio de régimen como un fenómeno meramente político, dejando a un lado todo un conjunto de condicionantes que estuvieron presentes en esos años. En esta interpretación los deseos y aspiraciones de la sociedad apenas si aparecen, quedando al margen de los acuerdos y acciones llevadas a cabo por los líderes políticos. Y por otro lado, frente a esa interpretación no dejan de aparecer en los últimos años diferentes trabajos que enfatizan el papel jugado por los movimientos sociales de oposición al franquismo, el comportamiento colectivo y en definitiva la construcción de la democracia ${ }^{1}$. Es preciso señalar como la movilización y la protesta colectiva contribuyeron a facilitar el camino de la transición a la democracia al desgastar políticamente la dictadura franquista, desafiando su capacidad para mantener el orden social sobre el que fundamentó su propia existencia y erosionando su cohesión conforme se enfrentó a dicha amenaza ${ }^{2}$. La oposición franquista de los años sesenta y setenta aglutinaba tanto a trabajadores, como a la nueva y vieja izquierda, estudiantes, vecinos, amas de casa, organizaciones de mujeres, organizaciones autonómicas e independentistas y una nueva generación de católicos y representantes de la Iglesia, que aspiraba y manifestaba de forma expresa el deseo de transformación y democracia ${ }^{3}$.

1. Cruz, Rafael y Pérez, Manuel (eds.), Cultura y movilización en la España contemporánea, Madrid, Alianza Universidad, 1997, p. 38.

2. Collier, Ruth B., Paths Toward Democracy. The Working Class and Elites in Western Europe and South America, Cambridge, Cambridge University Press, 1999, p. 20.

3. Para esta cuestión, véase Maravall, José $\mathrm{M}^{\mathrm{a}}$, Dictadura y disentimiento político. Madrid, Alfaguara, 1978; del mismo autor La política de la transición, Madrid, Taurus, 1981; Míguez, Santiago, La preparación de la transición a la democracia en España, Zaragoza, Universidad de Zaragoza, 1990; PÉREZ-DíAz, Víctor, The return of civil society: the emergente of Democratic Spain, Cambridge, Harward University Press, 1993; FisHman, Robert, 
En este sentido, afortunadamente en los últimos años se está produciendo una renovación metodológica proporcionada por la historiografía de género, al igual que la reformulación de la historiografía de la resistencia como categoría, concediéndosele un mayor sentido e importancia a otros agentes sociales. Así pues, está surgiendo una importante bibliografía que se ha aproximado a las luchas concretas de mujeres en los últimos años del franquismo, centrándose sobre todo en el papel del movimiento de mujeres y en el resurgir del feminismo con la llegada de la democracia ${ }^{4}$. Nuestra intención es prestar atención a aquella etapa de toma de conciencia de las mujeres a finales de la dictadura enmarcada en el espacio socio-político del antifranquismo. Es preciso entender la resurrección del feminismo español dentro del marco de oposición social contra el franquismo, situación que influirá directamente en la naturaleza del movimiento feminista, que luchará no sólo por la defensa de valores feministas, sino también por aquellos propiamente democráticos y que llevaron a un variado repertorio de formas de lucha contra la dictadura. En palabras de Mary Nash "el feminismo surgió como una respuesta individual y colectiva contra el régimen de Franco como sistema político dictatorial y, también, contra la misoginia y la discriminación sexista inherente en el sistema jurídico y político patriarcal del franquismo"s.

Organización obrera y retorno a la democracia en España, Madrid, CIS, 1996; HamanN, Kerstin, "Civil society and democratic transisition in Spain", Perspectives on Political Science, Washington, 27/3 (1998), p. 135-141; McAdam, Doug, Tarrow, Sidney y Tilly, Charles, Dinámica de la contienda política, Barcelona, Hacer, 2005.

4. A modo de ejemplo destacan especialmente las publicaciones de NASH, Mary, Dones en Transició. De la resistència política a la legitimitat feminista: les dones en la Barcelona de la Transició, Barcelona, Ajuntament de Barcelona y Regidoria de la Dona, 2007; de la misma autora, "El moviment feminista durant la Transici", en PAGÉs I Blanch, Pelai (ed.), La transició democrática als Paisos Catalans. Història i memoria, Valencia, Publicacions de la Universitat de València, 2005, así como la coedición con TORRES, Gemma, Feminismo en la transición, Barcelona, Grup de Recerca Consolidat Multiculturalisme I Genere-Universitat de Barcelona, Sociedad Estatal de Conmemoraciones Culturales, 2009; LARRUMBE, Ma Ángeles, Una inmensa minoría: influencia y feminismo en la transición en la transición, Zaragoza, Prensa Universitaria de Zaragoza, 2002; de la misma autora, Las que dijeron no. Palabra y acción del feminismo en la transición, Zaragoza, Prensa Universitaria de Zaragoza, 2004; Agustín PuerTa, Mercedes, Feminismo: identidad personal y lucha colectiva, Granada, Universidad de Granada, 2003; SuÁREZ, Carmen, Feministas en la transición asturiana (19751983), Oviedo, KFK, 2003; Escario, Pilar, AlBERDI, Inés y LóPeZ, Ana Inés, Lo personal es político: el movimiento feminista en la transición, Madrid, Instituto de la Mujer, 1996; AsoCiación de Mujeres en la Transición Democrática, Españolas en la Transición: de excluidas a protagonistas (1973-1982), Madrid, Biblioteca Nueva, 1999; Moreno, Amparo, Mujeres en lucha. El movimiento feminista en España, Barcelona, Anagrama, 1977; CUESTA, Josefina (dir.), Historia de las mujeres en España: siglo XX, vol. II, Madrid, Instituto de la mujer, 2003; Martínez, Carmen, GutiérRez, Purificación y GonzÁlez, Pilar, El movimiento feminista en España en los años setenta, Madrid, Cátedra, 2009.

5. NASH, Mary, "La construcción de una cultura política desde la legitimidad feminista durante la transición política democrática", en AgUAdo, Ana y ORTEGA, Teresa Mª, 
Nuestro objetivo, por tanto, es tratar de analizar ese período de formación de la conciencia feminista a través del estudio del Movimiento Democrático de Mujeres, representante de la lucha por los derechos civiles y la democracia, además de los específicos femeninos, destacando su doble lucha: política y social. Política en función de su importante oposición al régimen a partir de su labor por la amnistía y por los presos políticos, siendo un espacio de encuentro y aprendizaje político para aquellas mujeres que se adentraron en la militancia político-feminista a finales de los sesenta y principios de los setenta; y social a partir de su batalla por un reconocimiento social basado en la igualdad. Es básico a la hora de definir el propio concepto de ciudadanía, tener en cuenta que no sólo se ciñe únicamente a la esfera de reivindicación evidente y consciente de derechos de ciudadanía, sino también a la interacción compleja de diferentes movimientos sociales y grupos que trabajan en la esfera de la política y de lo público. La definición clásica de ciudadanía de T. H. Marshall se centra en tres dimensiones básicas política, civil y social ${ }^{6}$, de forma que permite identificar dos tipos de democracia. La democracia formal que reconoce los derechos civiles y políticos en igualdad de condiciones, y la democracia sustantiva, que reconoce junto a los anteriores los derechos sociales en igualdad de condiciones. Pero además, la ciudadanía necesita el funcionamiento de una colectividad que reconozca la subjetividad activa de los ciudadanos ${ }^{7}$. Como indica Mary Nash "la ciudadanía tiene que ver con la pertenencia a una comunidad que confiere derechos y responsabilidades" un sentimiento de pertenencia a una sociedad que hace partícipe a sus miembros en la práctica de la ciudadanía. En este contexto, sería interesante analizar si las mujeres fueron cooperantes a la hora de levantar una comunidad ciudadana que les hiciera partícipes, y si sus acciones y reivindicaciones fueron capaces de ensanchar el espacio de la ciudadanía para agregar derechos en el proceso de la transición democrática. No se pretende hablar de ellas como un apéndice y algo más, sino de analizar el proceso histórico teniendo en cuenta que los actores principales van a tener distintas experiencias de vida y sociales en función de su diferente identidad de género. En este sentido, es interesante ver como las múltiples identidades feministas, lo que nos lleva es a "refle-

Feminismos y antifeminismos. Culturas políticas e identidades de género en la España del siglo XX, Universitat de València y Universidad de Granada, Valencia, 2011, p. 285.

6. Marshall, Thomas Humphrey, Class, Citizenship ans Social Development, Cambridge, Cambridge University Press, 1950.

7. García, Soledad y LuKES, Steven (comps.), Ciudadanía, justicia social, identidad y participación, Madrid, Siglo XXI, 1999.

8. NASH, Mary, "La construcción de una cultura política..., p. 286. 
xionar sobre la historicidad del propio feminismo como cultura política en sí misma, con sus propios lenguajes y prácticas discursivas"9. Además, en un contexto de represión, la simbiosis de un enfoque de clase junto con un análisis de género puede permitir dar luz a ciertas zonas en las que mujeres de una determinada clase social defendieron sus intereses de género y de clase, pusieron en marcha ciertas estrategias de lucha, o algo tan simple como la supervivencia ${ }^{10}$.

\section{De la solidaridad a la movilización de la mujer: el nacimiento del MDM}

Aquellas mujeres que se involucraron con la oposición antifranquista en los primeros años de la dictadura lo tuvieron que hacer acomodándose no sólo al modelo nacional-católico patriarcal, sino también en medio de la lucha clandestina donde su posición era secundaria. El PCE, abanderado de la resistencia antifranquista, pese a su llamamiento para incorporarlas a la lucha contra la dictadura, siguió la línea de que sólo bajo la lucha de la clase trabajadora era posible el éxito socialista y acabar con cualquier tipo de esclavitud, incluida la femenina. En esta época las militantes comunistas a pesar de realizar una importante labor en la clandestinidad, tuvieron un escaso reconocimiento, ya que su tarea era considerada como algo secundario y auxiliar dedicándose a la distribución de propaganda, enlaces, ayuda a los presos políticos... Esta situación fue asumida por éstas ya que "su conciencia de género estaba claramente supeditada a su conciencia de clase"11.

Sin embargo, fueron muchas, algunas militantes, las que se hicieron cargo no sólo del núcleo familiar, sino también de llevar a cabo toda una red asistencial y de solidaridad a favor de sus familiares encarcelados, llegando incluso a protagonizar una intensa actividad reivindicativa ${ }^{12}$. Podemos plantearnos si

9. Aguado, Ana, "La historia de las mujeres y del género", Ortega, Teresa Ma (coord.), Historia global. El debate historiográfico en los últimos tiempos, Granada, Prensas Universitarias de Zaragoza, 2007, p. 124.

10. Sobre el género y la formación de la clase, véase AGuADo, Ana, "Las relaciones de género y la nueva historia social. Identidad y prácticas culturales", en El siglo XX: balance y perspectivas, Valencia, Fundación Cañada Blanch, Universitat de València, 2000, pp. 159-164; de la misma autora, "La historia de las mujeres y del género"... Igualmente, destacan los trabajos recogidos en CAmpos, Concepción y GonZÁlez, Ma José (coord.), Mujeres y dictaduras en España y América Latina: el largo camino, Universidad de Málaga, Málaga, 1996.

11. Miguel GonZÁLEZ, Román, "Las culturas políticas del republicanismo histórico español", Ayer, $\mathrm{n}^{\circ}$ 53, (2004), p. 213.

12. Moreno, Amparo, "La réplica de las mujeres al franquismo", en Folguera, Pilar, El feminismo en España: dos siglos de historia, Madrid, Siglo XXI, Madrid, 2007, pp. 123-156; CABRERO, Claudia, Mujeres contra el franquismo (Asturias 1937-1952): vida cotidiana, repre- 
pudo o no existir una resistencia al franquismo específicamente femenina, destacando en este momento la toma de conciencia de muchas mujeres anónimas que nunca habían desarrollado una actividad militante durante la República, pero que fueron testigos de cómo la represión caía directamente sobre sus familiares. Además, sobre ellas comenzó a extenderse una mancha, que les haría más difícil si cabe no sólo la lucha por asegurar la supervivencia de la familia sino también contra el olvido de los suyos, convirtiéndose en un acto de rebeldía frente a la realidad existente. Será precisamente en medio de este tipo de acciones, realizadas de forma colectiva, donde se manifiesta la conciencia femenina a la que se refiere Temma Kaplan ${ }^{13}$. Es así como, en una sociedad donde la convivencia y las formas de sociabilidad se quebraron por la guerra civil y la represión, esposas, madres e hijas encontraron especialmente en las puertas de las cárceles un punto en el que se reconocieron y establecer lazos de solidaridad y afinidad, dando comienzo a algo parecido a un sistema de resistencia propiamente femenino. Así pues, se fueron tejiendo unas redes de solidaridad, que les dio la posibilidad de organizar colectivamente un entramado asistencial a los presos, que en ocasiones fue más allá de la simple ayuda material, colaborando con la introducción de propaganda o viceversa, siendo el enlace entre el interior y el exterior. Poco a poco diversos actos de protesta reivindicando la mejora de las condiciones de vida de los presos fueron tomando paulatinamente un carácter más político, señalando como dice Giulana di Febo "para la mujer del detenido empezó una nueva forma de vivir, de actuar, de pensar: ser mujer de preso, además de símbolo y testimonio de la represión se convertía en estos años en una función política"14. Es así como nacieron las "mujeres de preso", que a través de la creación de fuertes vínculos de solidaridad que fortalecieron su movilización política en pro de la libertad de sus familiares

sión y resistencia, Oviedo, KRK, 2006; YUSTA, Mercedes, "Las mujeres en la resistencia antifranquista, un estado de la cuestión", Arenal, 12 (2005), pp. 5-24; ABAD, Irene, "El Movimiento Democrático de Mujeres de Zaragoza y su función en torno a los presos políticos del franquismo", VI Encuentro de Investigadores sobre el franquismo, Zaragoza, 2006, pp. 635-650; GARCíA, Ramón, "Mujeres en vanguardia. La resistencia femenina al franquismo en la cuenca minera asturiana, 1962-1967", en Tiempos de Silencio. Actas del IV Encuentro de Investigadores del franquismo, Valencia, 1999, p. 341-345; Díaz, Pilar, "La lucha de las mujeres en el tardonfranquismo: los barrios y las fábricas" Gerónimo de Uztariz, 21 (2005), pp. 39-54.

13. Kaplan, Temma, "Conciencia femenina y acción colectiva: el caso de Barcelona, 19101918” en S. Amelang, James y NASH, Mary (eds.), Historia y género: las mujeres en la Europa Moderna y Contemporánea, Valencia, Alfons el Magnànim, Institució Valenciana d'Estudis i Investigació, 1999, pp. 267-295.

14. Di FeBo, Giulana, Resistencia y movimiento de mujeres en España, Icaria, Barcelona, 1976, p. 87. 
presos, pasaron a un objetivo general de amnistía a los presos, suponiendo salir del campo asistencial de ayuda para formar parte activa del movimiento de oposición antifranquista ${ }^{15}$.

Su importante labor, generó un cierto cambio en la táctica del PCE respecto a la militancia femenina. Una de sus primeras iniciativas fue la creación en 1959 del boletín clandestino Mujer. En su primer número quedaron establecidos los objetivos de la publicación, centrados en la creación de grupos desde los que incorporar a las mujeres a la lucha contra la dictadura y potenciar su presencia en los comités del partido ${ }^{16}$. Es en ese entramado de lucha antifranquista donde comienza a gestarse en Madrid el inicio de una organización en la órbita del PCE, destacando el papel que tuvieron entre otras Carmen Rodríguez o Dulcinea Bellido, bajo la idea de luchar por los presos políticos, denunciar la represión y configurarse como una plataforma de solidaridad ${ }^{17}$. El aumento de la conflictividad y su papel apoyando las reivindicaciones del movimiento obrero propiciaron que los dirigentes del PCE intentaran reorganizar a las militantes que habían desarrollado labores de apoyo a los presos y al partido. En 1962 la dirección del PCE decidió reconstruir las juventudes del partido y crear una nueva asociación de mujeres que aglutinase a las mujeres de preso, a militantes y simpatizantes del PCE y a aquellas disidentes de los círculos intelectuales y el catolicismo progresista. Sin embargo, la idea no cuajó y muchas de las asistentes se desvincularon del proyecto ${ }^{18}$.

A pesar de esa contrariedad, las militantes más activas de ese momento siguieron tanteando la posibilidad de crear una organización femenina a partir de sus contactos con las mujeres de preso. Poco a poco y a partir de diferentes reuniones, trabajos de solidaridad y apoyo se fue gestando un embrión de organización, que nació en 1964 en Madrid bajo el nombre de Movimiento Democrático de Mujeres. Una organización clandestina que emergía destacando su naturaleza plural e interclasista, su apoyo a los presos y a sus familiares, su lucha antifranquista y su preocupación por los problemas de las mujeres.

15. ABAD, Irene, En las puertas de prisión. De la solidaridad a la concienciación política de las mujeres de los presos del franquismo, Barcelona, Icaria, 2012.

16. Mujer, $\mathrm{n}^{\circ} 1$, IX-1959.

17. Sobre esta cuestión veáse: ABAD, Irene, En las puertas de prisión...; CABrero, Claudia, "El PCE y las mujeres. La actitud del Partido respecto a la militancia femenina durante el primer franquismo", I Congreso sobre la Historia del PCE, 1920-1977, Oviedo, 2004, p. 427-440; SCAlon, Geraldine M., La polémica feminista en la España contemporánea, 1868-1974, Madrid, Akal, 1986, NASH, Mary, Rojas. Las mujeres republicanas en la Guerra Civil, Madrid, Taurus, 2000, pp. 111-127.

18. Arriero, Francisco, "El Movimiento Democrático de Mujeres: del antifranquismo a la movilización vecinal y feminista", Historia, Trabajo y Sociedad, nº 2 (2011), pp. 33-62. 
El PCE desde el primer momento dejó claro su papel como tutor, combinando la creación de un frente femenino que ampliara la influencia social del partido, junto con el deseo de luchar contra la discriminación sufrida por la mujer ${ }^{19}$. Así pues, Mary Nash destaca como el MDM surgió con una clara conexión con el PCE pero "fomentando desde la clandestinidad política, la movilización de las mujeres en las asambleas y vocalías de barrios (...) y desempeñó un rol decisivo al movilizar a las mujeres trabajadoras en los barrios periféricos en la lucha antifranquista. Además, su práctica facilitó una cierta incorporación de peticiones específicas" ${ }^{20}$. Del mismo modo, Mónica Tehrelfall señala que aunque el MDM no fue una creación exclusiva del PCE, sí que nació en sus filas y contó con su aprobación, sentando las bases de la participación de la mujer en la esfera pública de la oposición política ${ }^{21}$. Sin embargo, Romeu Alfaro apunta que la creación del MDM está más relacionada con la FDIM y la UME que con el PCE, y que su nacimiento está vinculado directamente con el contexto de agitación social de Madrid en los años sesenta formado por las militantes comunistas, pero al mismo tiempo "con el deseo de que se abriera a mujeres de distinta ideología y con el objetivo prioritario de sensibilizar a las mujeres tanto en los temas sociales y políticos de carácter general como en los más específicos femeninos como podía ser la discriminación legal y social"22. Desde esta misma óptica Sara Iribarren indica la particularidad del MDM teniendo en cuenta la realidad política del país $^{23}$. Así pues, se puede afirmar que precisamente esa combinación entre lo político y el feminismo fue su peculiaridad durante toda su existencia. Un complejo camino que no siempre fue entendido por todas sus militantes, que estuvo supeditado por la tutela del PCE y por los diferentes momentos por los que transcurrió la lucha antifranquista. De forma que, "el MDM es un movimiento de masas cuyo campo específico de acción es la masa femenina (...). El MDM liga este trabajo a la lucha socio-política general del país contra el franquismo (...); conscientes de que la liberación de la mujer va indisolublemente ligada a la liberación de la clase trabajadora"24.

19. Romeu Alfaro, Fernanda, Silencio roto... Mujeres contra el franquismo, Oviedo, edición de la autora, 1994.

20. NASH, Mary, Mujeres en el Mundo. Historia, Retos y Movimientos, Madrid, Alianza, 2004, p. 68.

21. Threlfall, Mónica (ed.), Mapping the women's movement. Feminist Politics and Social Transformation in the North, Londres y Nueva York, Ed. Verso, 1996.

22. Romeu, Fernanda, El silencio roto, mujeres... p. 74.

23. IribarRen, Sara, La liberación de la mujer, París, Ebro, 1972, p. 128-129.

24. ¿Qué es el MDM? Mujeres, sin fechar, Caja 117, carpeta 2. Archivo Histórico Partido Comunista de España (a partir de ahora AHPCE). 
Aunque desde el inicio la organización estuvo en manos de las militantes del PCE, desde muy pronto se fueron incorporando activistas socialistas, católicas e independientes, que de hecho no estaban en minoría respecto a las militantes y simpatizantes del $\mathrm{PCE}^{25}$, de forma que como señala $\mathrm{M}^{a}$ Ángeles Larrumbe el origen del MDM se debió a la iniciativa tomada por las militantes comunistas, uniéndose mujeres de otros sectores situación que le daría un carácter más plura ${ }^{26}$. Esta diversidad del movimiento quedó reflejado en varios números del boletín La mujer y la lucha indicando que "mujeres de diversas ideologías pero con los mismos problemas hemos trabajado juntas, codo con codo, sin reservas ni prejuicios anacrónicos, dando cada una lo mejor de nosotras mismas en la realidad de la lucha diaria"27, de modo que "tal fórmula bien puede ser un movimiento democrático de mujeres en el cual tengan cabida diferentes concepciones políticas y religiosas, condición indispensable para que se desarrolle y pueda aportar su influencia en el presente y futuro inmediato del país"28.

Aparte de la estrategia de movilización es importante destacar como empezaron a hacer públicas y a canalizar la lucha que los presos políticos no podían realizar desde el interior de las cárceles, entrando de lleno en un nuevo mundo, pasando de la sombra de sus casas a la luz de la calle, tratando de recuperar derechos y redefiniendo su posición dentro de la sociedad. Era bastante habitual que se reunieran para estudiar y planificar las tareas económicas, médicas y legales relacionadas con los presos. A partir de aquí se realizaba un intenso trabajo centrado en visitar a personalidades del régimen, el clero y diferentes centros oficiales, con el objetivo de plantear los problemas que los presos políticos sufrían en las cárceles, como malas condiciones, incomunicación con el exterior y sobre todo condenas excesivamente largas, para lo cual solicitaban una plena amnistía política. Un arduo trabajo que no siempre conseguía lograr sus objetivos, ejemplificado en una carta que se envía desde Jaén, señalándose la ingratitud de esta actividad, ya que tanto esfuerzo no se veía recompensado con grandes éxitos, aunque tampoco caía en saco roto ${ }^{29}$.

Tal fue la importancia de la ayuda a los presos y sus familiares que la Comisión de Solidaridad en 1968 se creó con el objetivo de realizar esa labor, aunque pronto se extendería a despidos por huelga y a la asistencia jurídica y médica en casos necesarios. Se demuestra el gran esfuerzo del MDM en este sen-

25. Informe de la organización de mujeres de Madrid. Madrid, 1969. Mujeres: Caja 117, carp. 2/3. AHPCE.

26. LARRUMBe, $\mathrm{M}^{\mathrm{a}}$ Ángeles, Una inmensa minoría...

27. La mujer y la lucha, XII/I-1969.

28. La mujer y la lucha, V-1971.

29. Correspondencia. Jaén. 1973. Represión franquista: Caja 40, carpeta 4. AHPCE. 
tido, ya que la recaudación solidaria entre familias obreras, de bajos ingresos y trabajadores podía pasar en cualquier momento de ser donantes a beneficiarios de estas ayudas. Pero, además esta comisión de solidaridad llegó a suponer para el MDM un espacio idóneo para captar aquellos lugares donde se iba a repartir el dinero y así extender la organización ${ }^{30}$. Como uno de los diferentes ejemplos podemos analizar el caso de Jaén. Esta práctica de solidaridad tenía sus precedentes antes de la creación del MDM. Rosario Ramírez, activa militante del PCE, llegó a realizar una tarea básica en beneficio de los presos y sus familiares ${ }^{31}$, destacando entre sus prioridades la distribución de alimentos a la vez que favorecer la estancia de los familiares, generalmente esposas, madres o hijas, que venían a la cárcel de Jaén a visitarlos. Solidaridad entre mujeres que iban tejiendo toda una red asistencial básica para su supervivencia, ya que "si no existían puntos de apoyo entre ellas, muchas de estas mujeres dormían en la estación, porque no tenían dinero ni para pagarse una pensión. Además había un gran esfuerzo de estas mujeres por sacar adelante a la familia y ayudar al preso"32. Pero además, esta intensa actividad no sólo reforzó sus lazos de unión, sino que también comenzó a crear una serie de intereses comunes diferentes a los tratados hasta ese momento de forma que "las reuniones que teníamos las mujeres de presos eran para hablar de las cárceles, pero el tema estaba tan sabido que empezamos a discutir otras cosas"33.

La importancia y diferencia del MDM respecto a otras organizaciones surgidas durante los primeros años sesenta fue su capacidad para desarrollar un movimiento a nivel nacional, estructurado a partir de pequeñas delegaciones de barrio, especialmente en las grandes ciudades. Este carácter urbano permitió al MDM servirse de la Ley de Asociaciones del 24 de diciembre de 1964 para constituirse legalmente como Asociaciones de Barrio, Asociaciones de Amas de Casa o Asociaciones de Amas de Hogar, fomentando de este modo la agrupación y politización de los barrios populares. En Madrid se crearon las primeras asociaciones de Getafe, Chamartín, Carabanchel y Ventas a lo largo de 1969 y 1970 inscribiéndose como asociaciones de Amas de Casa contando con 17 grupos que se reunían semanalmente ${ }^{34}$. A partir de este momento se

30. Informe de la Organización de Mujeres de Madrid. Madrid. 1969. Mujeres: Caja 117, carp. 2/3. AHPCE

31. Entrevista a Cayetano Rodríguez, Jaén, 31-V- 2007.

32. Entrevista realizada por Irene Abad a Carmen Casas recogida en ABAD Irene, "Las mujeres de presos republicanos: movilización política nacida de la represión franquista" en Documentos de Trabajo, $\mathrm{n}^{\circ} 2$ (2004), Fundación $1^{\circ}$ de mayo, p. 14.

33. Entrevista a Natalia Joga. Carpeta 285, cinta 314. Centro Documental de la Memoria Histórica (CDMH), Centro de Información y Formación Feminista (CIFFE).

34. Informe de la organización de mujeres de Madrid. Madrid. 1969. Mujeres, Caja 117, Carpe. 2/3. AHPCE. 
fue iniciando una labor de puerta a puerta de forma que "la utilización de plataformas legales nos permitirá llegar a esas miles de mujeres diseminadas y agruparlas en torno a problemas concretos. Hay una serie de Asociaciones de Amas de Casa distribuidas por todo el país que no hacen nada en torno a los problemas de la mujer (...) en los lugares que no existían, sería interesante estudiar la posibilidad de crear nosotras" 35 . El MDM entendía a la mujer como un "ser social afectado por la ausencia de libertades generales y doblemente discriminada por su condición de mujer"36 y en esa discriminación existe un protagonista que se convierte en su primer objetivo de captación: el colectivo de amas de casa. Para el MDM era el sector más numeroso y el más injustamente discriminado: "el ama de casa, a la que la sociedad actual imposibilita a participar en las tareas colectivas, mientras la agobia con problemas domésticos (...), acaparando todo su tiempo y mutilando su proyección humana, tiene la posibilidad y el deber de participar en la lucha reivindicativa (...) que le hace tomar parte activa $y$ consciente en los problemas comunes, consigue vincularla como ser social, sacándole del individualismo en que se haya sumergida con las tareas domésticas que le producen soledad, tedio y nerviosismo" 37 . El MDM buscaba la forma de que se sintieran "útiles, ser algo más que una máquina de fregar y coser... revelarles la importancia de la participación y la unión", aún cuando para las militantes del movimiento "es un trabajo ingrato, en ocasiones aburrido y que produce desazón"38. Utilizando una serie de mecanismos para concienciarlas como movilizaciones, protestas, manifestaciones y charlas en los barrios denunciando la carestía de vida, mejora en los salarios, o la falta de infraestructuras y equipamientos, el MDM pretendió poner sobre la mesa otras reivindicaciones sociales y políticas, que fueron planteadas de forma específica, ya que sin renunciar a sus "responsabilidades de género", solicitaban una mayor facilidad para mantener e incrementar su participación política, adaptándose cada vez más a un discurso feminista. La creación de las vocalías de la Mujer sentaron las bases para seguir luchando en un movimiento asociativo supuestamente igualitario, empezando a poner en marcha experiencias que convirtieron una reclamación feminista, como el derecho al propio cuerpo, en proyectos del Estado de Bienestar ${ }^{39}$.

35. Reunión Nacional de Mujeres de Madrid. Madrid. 1971. Mujeres: Caja 117, carp. 2/2. AHPCE.

36. Primera reunión general de las mujeres demócratas. Mujeres: Caja 117, carp. 2/2. AHPCE.

37. Tercera reunión general del Movimiento Democrático de Mujeres. Madrid. Mujeres: Caja 117, carp. 2/2. AHPCE.

38. Reunión Nacional de Mujeres, Madrid. 1971. Mujeres: Caja 117, carp. 2/2. AHPCE.

39. Muñoz, A. y Ramos, M.D., "Mujeres, política y movimientos sociales. Participación, contornos de acción y exclusión", BORDERÍAS, Cristina, (ed.), La historia de las mujeres: perspectivas actuales, Barcelona, Icaria, 2009, p. 102. 
Además, el hecho de que no se llegara a romper ese carácter de continuidad entre el espacio doméstico y el barrio da lugar a que las diversas reivindicaciones sean una prolongación más de las necesidades del hogar. El barrio pasa a ser el lugar ideal para la progresiva toma de conciencia femenina con el objetivo de ir venciendo el aislamiento ${ }^{40}$. Las asociaciones de los barrios sirvieron de plataforma para solucionar ciertas carencias en su formación y concienciación que impedían su capacidad para incorporarse al ejercicio de su derecho como ciudadanas $^{41}$. Ese hecho fue más que relevante a la hora de formar su propia conciencia en un escenario regulado por la falta de libertades, la oposición antifranquista y la lucha por la democracia, centrándose precisamente esa conciencia femenina en los derechos de género, en los intereses sociales y en la propia supervivencia, de forma que el principio que la legitima es la necesidad de conservar la vida, poniendo el acento en la lucha por el mantenimiento de la vida cotidiana que realizan las mujeres, en la línea seguida por Temma Kaplan ${ }^{42}$.

Ante su incorporación a la industria a lo largo de los años sesenta, las militantes de MDM, en su idea de crear un movimiento de masas de mujeres, también miraron con especial atención a la mujer trabajadora, criticando su destino laboral, ya que a pesar de su independencia económica y personal, en muchas ocasiones llegó a convertirse en un trabajo en cadena, de baja cualificación, e incluso en ocasiones vejatorio y que su participación en huelgas o sindicatos era algo ajeno a ellas, de forma que "cuando hay convocatorias de huelga se nos hacen advertencias que no se atreverían a hacer a nuestros compañeros. Se nos quiere hacer ver que tales problemas no son cosa nuestra, que nos son femeninos (...) organicemos en cada empresa o colegio, para unir nuestros esfuerzos a toda la lucha general, encabezada ya por grandes sectores del movimiento obrero del cual somos un destacamento más"43.

40. Sobre el papel de las mujeres en la lucha en los barrios, véase Di FEBO, Giulana, "La lucha de las mujeres en los barrios en los últimos años del franquismo. Un ejemplo de utilización de la "Historia de género", Tusell, Javier, Alted, Alicia y Abdón Mateos, La oposición al régimen de Franco. Estado de la cuestión y metodología de la investigación, t. II, UNED, Madrid, 1991, pp. 251-160; DOMĖNECH, Xavier, "Género antifranquismo y ciudadanía. Mujeres y movimiento vecinal en la Asturias del desarrollismo y el tardofranquismo", Historia del Presente, 16 (2001), pp. 9-26.

41. García-Nieto, Ma Carmen, "Marginalidad, movimientos sociales, oposición al franquismo. Palomeras, un barrio obrero de Madrid, 1950-1980", en Tusell, Javier, Alted, Alicia y ABdón Mateos, La oposición al régimen de Franco. Estado de la cuestión y metodología de la investigación, tom II, UNED, Madrid, 1991, p. 278.

42. Kaplan, Temma, "Luchar por la democracia: formas de organización de las mujeres entre los años cincuenta y los años setenta", AGUADo, Ana, Mujeres, regulación de conflictos sociales y cultura de la paz, Publicacions de la Universitat de València, 1999, pp. 89-109.

43. ¡Trabajadoras! ¡Compañeras! Madrid.1971. Mujeres: Caja 117, carp. 2/6. AHPCE. 
En este sentido, el MDM concebía que la mujer sufría una doble explotación, patriarcal y capitalista, debiéndose sumar a las reivindicaciones y movilizaciones sindicales. Así pues, es importante destacar el cambio de registro que el MDM usaba dependiendo del colectivo que se refiriera. Si al colectivo de amas de casa le apela desde reivindicaciones de barrio y prácticamente sin entrar en concepciones de género, cuando se refiere a la mujer trabajadora, desarrolla un discurso propiamente marxista, insistiendo en su doble explotación, mientras que cuando se refiere a estudiantes universitarias y a profesionales el discurso es plenamente feminista de forma que "el ser biológico de la mujer es el que determina su ser social" ${ }^{44}$. El objetivo, por tanto, era buscar una nueva ciudadanía, luchando por la capacidad de crear un movimiento de masas de mujeres siendo necesaria la unión interclasista, de ahí su importancia por aglutinar tanto a mujeres de diferente ideológica como de todo tipo (obreras, amas de casa, estudiantes, profesionales... $)^{45}$, "no porque seamos mujeres sino porque estamos discriminadas" ${ }^{46}$, encabezando según Giulana di Febo la mayor movilización de las masas femeninas desde la posguerra ${ }^{47}$.

Así, un sector del MDM fue evolucionando de la lucha contra la represión, la amnistía y la red asistencial a los presos políticos y a sus familiares hacia la formación de un discurso más comprometido con el feminismo a finales de los sesenta y a lo largo de los primeros años de la década de los setenta, ya que para muchas el MDM fue el mecanismo utilizado para colocar la movilización feminista dentro de la órbita del PCE contra la dictadura franquista. Exigir la amnistía para los presos políticos y las libertades se incluía dentro de un escenario más amplio que pasaba por terminar con el franquismo e iniciar una sociedad socialista. Sin embargo, otro sector señalaba que todo aquello también era compatible con la denuncia de la situación de la mujer. A partir de aquí su camino estuvo señalado por una contradicción interna entre la búsqueda de su discurso de clase y de género.

A raíz de la publicación del boletín La mujer y la lucha en 1968 comenzó a señalarse las dificultades que entrañaba ser mujer en la línea iniciada por Simón de Beavoir donde la subalternidad femenina es una construcción social y por Betty Friedan indicando en estos años que ellas tienen "problemas muy concretos, discriminaciones claras y una mística encubridora y ensalzadora de esa situación" ${ }^{48}$, destacando esa mística de la feminidad que denunciaba el malestar de

44. ¡A todas las mujeres universitarias! Mujeres: Caja 117, carp. 2/6. AHPCE.

45. Informe de Amaya. Madrid. 1970, Mujeres: Caja 117, carp. 2/3. Ref. 187/14, Cop. $23-$ 4-70. AHPCE.

46. La mujer y la lucha, X-1968.

47. Di Febo, Giulana, Resistencia... p. 158.

48. La mujer y la lucha, IV- 1968. 
la mujer y su sometimiento. Este proceso hacia posiciones feministas también se vio contribuido por la llegada al MDM de una nueva generación de jóvenes tanto católicas, como socialistas, sin partidos y estudiantes universitarias que tenían otra visión de la organización, iniciando un verdadero aprendizaje feminista a través su esfuerzo personal. A partir de aquí, una parte del MDM fue evolucionado hacia un feminismo moderado que no siempre fue entendido por el PCE, porque demostraba la fractura entre el discurso marxista de la mujer y la tónica habitual sexista en los partidos de izquierda y porque el MDM defendía la necesidad de las organizaciones de mujeres, aunque estaba de acuerdo con el PCE en unir fuerzas para luchar contra la dictadura.

En este punto de inflexión hacia el feminismo la celebración en febrero de 1970 de la primera reunión general del MDM marcó un antes y un después. A partir de aquí, sin abandonar la lucha por los presos y pro amnistía, se fue incorporando oficialmente la cuestión de género, de forma que el objetivo principal era "estudiar los problemas que afectan a la mujer en general, como ser social afectado por la ausencia de libertades generales y doblemente discriminada por su condición de mujer" ${ }^{\prime \prime 9}$. Para esa fecha ya existían en España numerosos grupos, asistiendo a esta reunión delegadas de varias provincias como Asturias, Alcoy, Guipúzcua, Madrid, Puertollano, Santander, Tarrasa, Valencia, Valladolid, Vizcaya y Guipúzcua. El resultado fue una enumeración de facilidades que Estado y Empresas debía ofrecer para que fuera posible la emancipación de la mujer como guarderías, escuelas públicas, plena admisión de la mujer casada al trabajo, fin de leyes discriminatorias..., destacando que junto a este tipo de demandas y "ligadas a la problemática general (...) entendemos que las exigencias de estos sectores son nuestras".

\section{La llegada de la democracia y el fin del MDM}

Los informes de las distintas reuniones generales celebradas entre 1970 y 1975 señalan como fueron numerosos los grupos del MDM que surgieron por toda la geografía, aunque solamente fueron algunas ciudades las que consiguieron un movimiento consolidado y estable, siendo allí donde se llegó a iniciar una búsqueda del discurso reivindicativo que incorporase las experiencias feministas que llegaban del exterior. El MDM intentó convertirse en un movimiento de carácter estatal, impulsando un discurso político coherente y estructurando una estrategia común. Prueba de ello fue que en la Segunda Reunión General del Movimiento Democrático de Mujeres celebrada en 1971 surgieron nuevos gru-

49. Primera Reunión General de las Mujeres Democráticas, Madrid. 1970. Mujeres: Caja 117, carp. 2/2. AHPCE. 
pos, acudiendo delegaciones de Galicia, Murcia, Córdoba, Sevilla, Asturias, País Valencia, Madrid y Zaragoza, destacando la ausencia de País Vasco y Cataluña. Sin embargo, aunque llamó la atención esta proliferación de delegaciones, lo más significativo fue la composición de muchas de ellas, integradas por una nueva generación de jóvenes mujeres, sobre todo estudiantes de universidad, lo que implicó un cambio sustancial en la evolución del MDM.

La movilización del MDM en su lucha contra la represión franquista se compaginaría con otras reivindicaciones, ampliando el campo de acción femenino. Además, no debemos de olvidar que a lo largo de los setenta las integrantes del MDM empezaron a entablar relaciones con grupos feministas como el Movimiento de Liberación de la Mujer. Este doble discurso tendría repercusiones en el interior del MDM, llegándose a producir un choque generacional, puesto que algunos planteamientos más avanzados del feminismo como la defensa del aborto, la autodeterminación del cuerpo y la sexualidad femenina junto con una actitud más autónoma fueron defendidos por las militantes más jóvenes, muchas de ellas también integradas en el $\mathrm{PCE}^{50}$, mientras que las más mayores pensaban que esos temas asustaban a las amas de casa y tenían una menor importancia en relación con la reivindicación política y la lucha en los barrios. Esta situación provocó en el seno del MDM que muchas de sus componentes, sobre todo las que consideraban que el feminismo era incompatible con el comunismo, decidieran abandonar el grupo.

Sin embargo, a pesar de las disidencias internas, el objetivo del MDM seguía siendo la lucha por la emancipación femenina, aunque la amnistía política de presos y exiliados protagonizó buena parte de las movilizaciones y acciones del grupo, y es que no debe extrañar la atención que el MDM prestó durante los años setenta a la amnistía. Como se señala en un artículo del Mundo Femenino en 1971: “(...) ¿Cómo, pues, podemos las mujeres asturianas participar directamente en la lucha por la AMNISTÍA? Llevando esta exigencia a todos los lugares posibles, a las fábricas, a las tiendas, a las oficinas, a la calle; explicando a todo el mundo el por qué de la amnistía, ayudando en la recogida de fondos para las familias de presos y despedidos; enviando cientos de cartas o telegramas (a poder ser colectivos) a las diversas autoridades españolas, solidarizándose con las mujeres de los presos, que de diversas maneras tratan de conseguir su libertad; o participando en las manifestaciones, huelgas, encierros o cualquier otra forma de lucha"51. El MDM se centró en hacer ver a la sociedad y a la oposición antifranquista la

50. ERICE, Francisco, "Mujeres comunistas. La militancia femenina en el comunismo asturiano, de los orígenes al final del franquismo", en ERICE SEBARES, Francisco (coord.), Los comunistas en Asturias (1920-1982), Gijón, 1996, p. 334.

51. Mundo Femenino. Portavoz del Movimiento Democrático de Mujeres. Asturias. IX-1971. 
importancia de la reclamación de los derechos de la mujer para conseguir la igualdad. De hecho en la tercera reunión general que tuvo lugar en octubre de 1971 se decidió la "constitución de una coordinadora general que agilice los contactos e intercambios de experiencias de unos y otros lugares para impulsar decisivamente la incorporación de la mujer a la lucha"52. A la vez se insistía en la independencia y autonomía del movimiento, y la incorporación al mismo de todas las mujeres "sin distinción de ideologías o credo religioso".

Si en dos años se habían celebrado tres reuniones generales, no fue hasta agosto de 1975 cuando tuvo lugar la cuarta reunión general del MDM y última en la dictadura. Se difundió la idea de unidad social en torno al concepto de democracia por métodos pacíficos. Conceptos como unidad y democracia se emplearon para sustituir a independencia, lucha de clases y socialismo. Junto a la continuidad del discurso de amnistía, destacó también la lucha contra la pena de muerte. Es ahora por primera vez cuando en una reunión general no se trató el tema de los movimientos feministas, sino que se habló del Movimiento de Liberación de la Mujer, dejando claro que su objetivo de crear un movimiento de masas de mujeres estaba superado, dando paso a una reflexión sobre la discriminación de la mujer.

La concepción del capitalismo como base de todas las discriminaciones sociales, convertiría cualquier conquista femenina alcanzada dentro de dicho sistema en derechos formales de la burguesía, que beneficiaban sólo a un reducido número de mujeres. Como indica María José Valverde la actitud de las propias militantes, silenciadas durante años por el Régimen y sometidas a la conciencia de partido, fue la de aparcar sus "demandas específicas", mientras no se alcanzasen los mínimos generales ${ }^{53}$. Ante este hecho, aquellas militantes del PCE que no estuvieron de acuerdo con la decisión y no aceptaron que un partido se adjudicara un derecho que no le correspondía, rompieron con el PCE y decidieron seguir trabajando en el MDM, que siguió desempeñando un destacado papel en el conjunto del movimiento feminista ${ }^{54}$. A pesar de ello, las que se quedaron en el PCE trabajaron por introducir un profundo debate sobre la opresión de la mujer con posiciones muy avanzadas. Además, en el partido se cuestionaba el papel secundario de la militancia femenina afirmándose que "somos conscientes de que en nuestras filas, la discriminación de la mujer es una

52. Tercera Reunión General del Movimiento Democrático de Mujeres. Madrid. 1971. Mujeres: Caja 117, carp. 272. AHPCE.

53. Valverde, $M^{a}$ José, "La Mujer y el Partido Comunista de España", en JimÉnez, $M^{a}$ Jose (coord.), Pensamiento, imagen, identidad: a la búsqueda de la definición de género, Málaga, Servicio de Publicaciones de la Universidad de Málaga, 1999, pp. 111-115.

54. Larrumbe, $\mathrm{M}^{\mathrm{a}}$ Angeles, Una inmensa minoría... p. 156. 
realidad", así hay que luchar para que "las mujeres sean tenidas en cuenta en toda la vida y actividad de los comités del partido y no sólo para ayudar con trabajos prácticos" $" 55$. El MDM se enfrentó a los problemas de una doble militancia debido a la falta de solidaridad de los movimientos sociales y políticos que entendían su lucha como algo auxiliar. A pesar de ello, cada vez se hizo más frecuente la idea de que el proletariado no podía alcanzar el éxito completo sin la libertad de la mujer ${ }^{56}$, de forma que la contribución del feminismo se debía incorporar para impedir un socialismo a medias, definiéndose el propio PCE como un partido feminista y de liberación de la mujer ${ }^{57}$.

Sin embargo, realmente no se fomentaron acciones que incrementase la presencia femenina en el seno del PCE entre otras razones porque se priorizó la lucha contra la dictadura franquista y el pensamiento marxista clásico y por el peso que seguía teniendo el estereotipo de género en la militancia comunis$\mathrm{ta}^{58}$. En la práctica el PCE estimó que la función del MDM había de darse por concluida. Además, fue bastante frecuente que buena parte de las integrantes mejor formadas del MDM fueran captadas por el PCE u otros partidos. E incluso desde los partidos y comisiones se consideraba que sus militantes más activas no deberían perder el tiempo en organizaciones de mujeres ${ }^{59}$.

La lucha por la mujer tras la muerte de Franco siguió su curso hasta que en 1976 y en medio de la coyuntura de efervescencia del feminismo el Movimiento Democrático de Mujeres unió sus siglas a las del Movimiento de Liberación de la Mujer constituyéndose el MDM/MLM. El objetivo fundamental del grupo fue desarrollar una estrategia con un perfil más feminista, creando nuevas comisiones de enseñanza y universidad, para trabajar de forma más específica en estos sectores. Prueba de ello fue su participación en las Jornadas Nacionales por la Liberación de la Mujer, celebradas en el contexto del Año Internacional de la Mujer en Madrid entre el 6 y el 8 de diciembre de 1975, donde se constituyó una Coordinadora de Organizaciones Feministas a nivel nacional, y donde se excluía a Sección Femenina. Después vendrían los encuentros de las Jornadas Catalanas de la Dona en mayo de 1976, y las II Jornadas Estatales de la Mujer, que tuvieron lugar en Granada en 1979. Es en este escenario donde las mujeres debatieron sobre feminismo y trataron de buscar pun-

55. Mundo Obrero, $\mathrm{n}^{\circ}$ 32, X-1975.

56. El Correo del Pueblo, $\mathrm{n}^{\circ} 47,29-06-1976$.

57. Mundo Obrero, no 29, IX-1975 y no 30, X-1975

58. Para estas cuestiones véase VAlVerde, $\mathrm{M}^{\mathrm{a}}$ José, "La mujer y el Partido Comunista"...; CABrero, Claudia, "El PCE y las mujeres"... y Erice, Francisco, "Mujeres comunistas"...

59. Entrevista a Begoña San José, (BIO-003), realizada por Benito Bermejo y José Babiano. Madrid. 2002. Fundación Primero de Mayo. 
tos de encuentro en relación a las reivindicaciones, tácticas y estrategias necesarias para lograr la liberación de la mujer. Sin embargo, es preciso indicar que todos aquellos colectivos de mujeres que fueron surgiendo en el ocaso de la dictadura coincidieron en señalar un objetivo común: el fin de la dictadura y el desmontaje de su estructura era una condición básica para la supervivencia del movimiento feminista. Es más el hecho de que en estos momentos la campaña por la amnistía política siguiera ocupando una posición fundamental dentro de toda la movilización antifranquista, hizo que la nueva organización MDM-MLM no dejara de formar parte de campo de acción que constituía la oposición, aportando su presencia en la movilización pro-amnistía. Así, se empezó a converger en las propuestas del feminismo de la igualdad que defendía la democracia y aprobaba la participación de las mujeres en los partidos, señalando que la lucha por la democracia se completaba con la lucha feminista, defendiendo la doble militancia política y feminista. Esta postura fue criticada por el feminismo radical que defendía una militancia única en los grupos u organizaciones políticas de mujeres ya que cuestionaba los modelos de sociedad capitalita y comunista por no ofrecer soluciones a la opresión de la mujer, debido a que era la clase oprimida y explotada por el hombre. Sin embargo, las integrantes del MDM se justificaron del ataque de las feministas radicales señalando que éstas no tenían en cuenta el contexto político de España, ya que sin democracia y libertad la liberación femenina era imposible. Finalmente, esta línea del feminismo radical dio lugar a la creación en 1979 del Partido Feminista, ayudando al desarrollo de una nueva cultura política feminista ${ }^{60}$.

La propia dinámica de la democracia y la llegada de las elecciones de 1977 fueron apagando lentamente la actividad del MDM/MLM debido fundamentalmente al hecho de que la doble militancia se fue decantando hacia la estrategia de los partidos políticos, ya que buena parte de las militantes del Movimiento se inclinaron por los partidos políticos para luchar por la igualdad desde el poder, priorizaran el apoyo a las estrategias de los partidos de izquierda durante la Transición y relegando a un segundo plano su propia lucha ${ }^{61}$. El hecho de

60. GrAU, Elena, "De la emancipación a la liberación y la valoración de la diferencia. El movimiento de mujeres en el Estado español, 1965-1990", Duby, Georges y Perrot, Michelle (dir.), Historia de las mujeres. El siglo XX. Vol. 5, Madrid, Taurus, 1993, pp. 673-683; FAGOAGA, Concha y LunA, G. Lola, "Notas para una historia social del movimiento de las mujeres: signos reformistas y signos radicales", GARCíA-NiETO, Ma Carmen, Ordenamiento jurídico y realidad social de las mujeres. Siglos XVI- XX, Madrid, U.A.M., 1986, p. 453-462; Agustín, Mercedes, Feminismo: identidad personal y lucha colectiva (análisis del movimiento feminista español en los años 1975 a 1985), Granada, 2033; NASH, Mary, Mujeres en el mundo. Historia, retos y movimientos, Alianza, 2004.

61. Entrevista a Rosario Vicente, Jaén, 29-IX- 2008. 
que muchas mujeres se decidieran a luchar por la democracia y los derechos de género en sus propios partidos dio lugar a que creasen otros movimientos femeninos que quedaron insertados dentro de sus grupos políticos ${ }^{62}$. Una práctica habitual en los partidos de izquierda fue la creación de comisiones específicas para la mujer, que consiguieron de alguna forma introducir reivindicaciones feministas en sus programas. Ese fue el caso del PCE, que con la Comisión para la Liberación de la Mujer o para la Cuestión Femenina consiguió introducir reivindicaciones feministas reclamando "el final de la derogación de todas las discriminaciones jurídicas y la amnistía para todas las mujeres condenadas por motivos políticos, abandono de hogar, adulterio y aborto"63. Por su parte, el PSOE se decidió en 1976 a crear el colectivo Mujer y Socialismo cuyo objetivo fue crear centros asesores de la mujer para ayudarlas a resolver sus problemas en diferentes aspectos como profesionales, formativos o familiares. Igualmente, en partidos de extrema izquierda como el PTE o el MC se puso el acento en apoyar toda propuesta sobre el avance de la liberación de la mujer, de forma que el PTE llegó a asumir el programa de las Jornades Catalanes de la Dona y el MC destacaba que alrededor de un tercio de sus militantes eran mujeres. Sin embargo, en ambas organizaciones se seguía insistiendo en que aunque de forma más sutil se seguía manteniendo la subordinación de la mujer, situación que se debía remediar ${ }^{64}$, aunque en los programas políticos se fueron incorporando reivindicaciones básicas del movimiento feminista como la ley del divorcio, la igualdad ante la ley, el aborto, el uso de anticonceptivos, etc.

Así pues, poco a poco desde los inicios de la transición hasta los años ochenta el MDM fue desapareciendo de la geografía española. Los diferentes grupos fueron concluyendo sus actividades, quedando tan sólo algunos testimonios orales de cómo se fue diluyendo en el tiempo la actividad del MDM. En este sentido, por ejemplo en Jaén el MDM "ya no tenía sentido seguir luchando, además estaba el hecho de que se creía que se había conseguido ya sus objetivos"65, o lo señalado por Rosalía Sender en Valencia "dejé de participar en el MDM a principios de 1980 (...) el Movimiento Democrático de Mujeres siguió existiendo unos pocos años más, pero cada vez acudían menos mujeres a las reuniones, faltaba dinamismo y entusiasmo (...), poco a poco se fueron espaciando las reuniones"66.

62. SENDER, Rosalía, Luchando por la liberación de la mujer. Valencia. 1969-1981, Valencia, Publicacions de la Universitat de València, 2006, pp. 177-178.

63. Mundo Obrero, $n^{\circ}$ 43, 01-12-1976.

64. Ruiz, Fernando y Romero, Joaquín, Los partidos marxistas. Sus dirigentes, sus programas, Barcelona, 1977.

65. MARTínez, Irene "Tomar conciencia", Alsur, 11 (1993), p. 35.

66. SENDER, Rosalía, Luchando por la liberación..., p. 178. 


\section{Conclusiones}

En las páginas anteriores hemos analizado como el MDM fue una organización donde se encontraron varias generaciones de mujeres que lucharon contra la dictadura franquista. Su nacimiento se encuentra ligado al trabajo de muchas mujeres en el entorno del PCE, que realizaron toda una labor asistencial y de solidaridad a favor de sus familiares encarcelados. Así, llevaron a cabo una red de denuncia de la política represiva del régimen, trasladando a los barrios obreros la conflictividad social de finales del franquismo. Sin embargo, muchas de estas mujeres que se integraron en el MDM comenzaron a desarrollar un discurso feminista compatible con la lucha por la democracia y la libertad. Poco a poco el MDM se fue extendiendo por la geografía española, aunque sólo en algunas ciudades se alcanzó un movimiento estable y consolidado. En estos nuevos grupos que fueron apareciendo se integraron una nueva generación de jóvenes mujeres que implicaron un cambio fundamental en la evolución del Movimiento. A partir de estos momentos la lucha por el feminismo iba a tener cada vez más influencia. El MDM comienza a considerar un elemento básico la participación de la mujer en la oposición al franquismo, pero desde una posición de igualdad respecto al hombre. En este escenario fueron surgiendo un conjunto de protestas que influirían en todos los niveles en los que la mujer empezaba a estar representada, no sólo en la familia, sino también en la esfera laboral, en los barrios... La movilización de las mujeres del MDM en su lucha contra la represión franquista comenzó a compaginarse con otras reivindicaciones, ampliando su campo de acción. Así, se manifestaron contra la carestía de vida, la falta de guarderías, zonas verdes, además de denunciar la falta de posibilidad de la mujer y algunos planteamientos más avanzados del feminismo. En definitiva, protestas y luchas que fueron planteadas de forma específica, ya que sin llegar a renunciar a "sus responsabilidades de género" solicitaban una mayor facilidad para mantener e ir incrementando su participación política. 